\title{
A renaissance man
}

\author{
Thomas L. Slovis • Walter E. Berdon
}

Received: 30 September 2009 / Accepted: 30 September 2009/Published online: 16 December 2009

(C) Springer-Verlag 2009

It is rare for a pediatric radiologist to get front-page headlines in The New York Times-especially when he did nothing wrong [1]. Au contraire, H. Theodore (Ted) Harcke is doing pioneering work as chief of forensic radiology at the Armed Forces Institute of Pathology (AFIP) (see commentary "The Case for Postmortem Imaging"). Those who know Ted are not surprised.

Ted has had an extraordinary career, graduating from the U.S. Military Academy at West Point with a degree in engineering, serving in active duty in the Army, and then pursuing a master's degree in education (mathematics) and medical school at Pennsylvania State University College of Medicine. His medical training took him to Children's Hospital of Philadelphia (internship), Temple University Medical Center (radiology residency), and St. Christopher Hospital for Children (fellowship in pediatric radiology). He was chairman of the Department of Medical Imaging at Alfred I. DuPont Institute in Wilmington, DE, from 1983 to 1995 and held professorships at Temple University School of Medicine, Medical College of Pennsylvania, Jefferson Medical College, and Uniformed Services University of
Health Sciences. He served as a visiting scientist at the AFIP.

Ted has written extensively with emphasis on pediatric nuclear medicine, pediatric bone disease, and hip US. He is the innovator of dynamic sonography of the hip and taught most of us all we know about it.

Ted has found a new passion_-learning from the "virtual autopsy" so we can understand mechanisms of disease and devise ways to prevent traumatic injuries. It may seem odd to publish this material in a pediatric radiology journal, but to us, it is a continuation of our role from fetal to newborn to childhood imaging, and to postmortem imagingall designed to teach, inform, and, we hope, affect outcome. We should all learn from Ted and his inquisitive nature. We congratulate him on a job well done.

\section{Reference}

1. Grady D (2009) Autopsies of war dead reveal ways to save others. New York Times. May 26. Available via http://www.NYTimes. com/2009/05/26/health/26autopsy.html. Accessed 27 July 2009

Related articles can be found at doi:10.1007/s00247-009-1433-0 and doi:10.1007/s00247-009-1486-0.

T. L. Slovis $(\bowtie)$

Department of Pediatric Imaging,

Children's Hospital of Michigan,

3901 Beaubien Blvd.,

Detroit, MI 48201, USA

e-mail: pedradeditor@med.wayne.edu

W. E. Berdon

Departments of Radiology and Pediatrics, Columbia University,

Children's Hospital of New York,

New York, NY, USA 